\title{
Prognostic Value of Baseline Clinical and HRCT Findings in 101 Patients with Severe COVID-19 in Wuhan, China
}

\section{Yukun Cao}

Wuhan Union Hospital

\section{Xiaoyu Han}

Wuhan Union Hospital

Jin Gu

Wuhan Union Hospital

Yumin Li

Wuhan Union Hospital

Jia Liu

Wuhan Union Hospital

Osamah Alwalid

Wuhan Union Hospital

Yue Cui

Wuhan Union Hospital

Xin Zhang

Wuhan Union Hospital

Chuansheng Zheng

Wuhan Union Hospital

Yanqing Fan

Wuhan Union Hospital

Hanping Wu

University of Michigan

Heshui Shi ( $\square$ heshuishi@hust.edu.cn )

Wuhan union hospital

Research article

Keywords: COVID-19, Severe Pneumonia, Prognostic Value, High Resolution CT

Posted Date: May 20th, 2020

DOI: https://doi.org/10.21203/rs.3.rs-27790/v1 
License: (c) (i) This work is licensed under a Creative Commons Attribution 4.0 International License. Read Full License 


\section{Abstract}

Background It has been reported that patients with severe Coronavirus disease 2019 (COVID-19) had high mortality rate, but the information about prognostic factors for these patients is unknown. The aim of this study was to assess the prognostic value of baseline clinical and high resolution CT (HRCT) findings in patients with severe COVID-19.

Methods In this retrospective, two-center study, we included two groups of inpatients with severe COVID19 who had been discharged or had died in Jin Yin-tan hospital and Wuhan union hospital between January 5, 2020, and February 22, 2020. Cases were confirmed by real-time polymerase chain reaction. Demographic, clinical, laboratory data, and HRCT data were collected and compared between discharged and deceased patients. Univariable and multivariable logistic regression models were used to assess predictors of mortality risk in these patients.

Results 101 patients were included in this study, of whom 66 were discharged and 35 died in the hospital. The mean age was $56.6 \pm 15.1$ years and 67 (66.3\%)were men. Of the 101 patients, hypertension (38, $37.6 \%)$, cardiovascular disease $(21,20.8 \%)$, diabetes $(18,17.8 \%)$, and chronic pulmonary disease $(16,15.8 \%)$ were the most common coexisting conditions. The multivariable regression analysis showed older age (OR:1.142, 95\%Cl:1.059-1.231, p $₫ 0.001)$, acute respiratory distress syndrome (ARDS) (OR:10.142, 95\%Cl:1.611-63.853, $p=0.014)$, reduced lymphocyte count (OR:0.004, 95\%Cl: 0.001-0.306, $\mathrm{p}=0.013)$, and elevated HRCT score (OR:1.276, 95\%Cl:1.002-1.625, $\mathrm{p}=0.049)$ to be independent predictors of mortality risk on admission in severe COVID-19 patients.

Conclusions These initial data indicate that older age, ARDS, lymphocytopenia and elevated HRCT score on admission were strong predictors of mortality risk in severe COVID-19 patients.

\section{Introduction}

In December 2019, a cluster of cases of pneumonia of unknown etiology, now known as coronavirus disease 2019 (COVID-19), and the coronavirus was called severe acute respiratory syndrome coronavirus 2 (SARS-CoV-2), were reported in Wuhan, Hubei province, China[1-3]. Epidemiological studies have reported that most initial patients worked at or lived around a local seafood market in Wuhan and had human to human transmission [3, 4]. As of 16 April, 2020, a total of 2.0 million COVID-19 cases have been confirmed globally, including 140 thousand deaths across 200 countries, suggesting an enormous threat to the global public health [5].

Similar to human severe acute respiratory syndrome (SARS) and middle east respiratory syndrome (MERS), SARS-CoV-2 mainly causes lower respiratory tract infections[6, 7]. Previous studies have demonstrated the epidemiological, clinical characteristics and clinical outcome in patients with COVID-19, which range from mild to critically ill cases[2, 3, 8-10]. Yang et al[10] reported critically ill patients with COVID-19 having a considerable mortality, which puts tremendous pressure on hospital critical care resources. Some studies also revealed[11,12] risk factors associated with death of adult inpatients with 
COVID-19, including older age, high SOFA score, coagulation dysfunction, etc. However, specific information about mortality risk factors in critically ill patients remains unclear. In addition, the MuLBSTA score[13] indicated that the multi-lobular infiltrate assessed by chest radiography or CT imaging is the most important mortality risk factors in viral pneumonia patients. And Chen et al[3] reported the characteristics of deceased COVID-19 patients were in line with the score. Currently, High resolution computed tomography (HRCT) has been considered an important imaging modality in assisting the diagnosis and management of patients with COVID-19[14]. A large sample study showed that HRCT has a high sensitivity for diagnosis of COVID-19 in epidemic area[15]. However, the prognostic value of radiological findings in severe patients with COVID-19 was not reported, and previous studies[10, 12$]$ mainly focused on chest radiography rather than the more practical HRCT imaging.

In this study, we aimed to evaluate the prognostic value of baseline clinical and HRCT findings in severe patients with COVID-19.

\section{Methods}

\section{Study design and participants}

A retrospective two-center study was performed in Wuhan Jin Yin-tan hospital and Wuhan Union hospital (Wuhan, Hubei province, China). From January 5, 2020, to Feb 22, 2020, we enrolled two groups of patients (deceased and discharged patients) with severe COVID-19, who underwent HRCT scan at admission. All patients of confirmed infection with SARS-CoV-2 are in accordance with World Health Organization (WHO) interim guidance[16]. Throat swab samples were collected for confirmation of SARSCoV-2 by the real-time polymerase chain reaction assay as previously described[2, 3]. The diagnostic criteria for adult severe pneumonia was according to WHO interim guidance[17], which includes fever or suspected respiratory tract infection, plus one of followings: respiratory rate $>30$ breaths $/ \mathrm{min}, \mathrm{SpO} 2<90 \%$ on room air or severe respiratory distress. The discharge criteria for patients was according to the sixth edition of "pneumonia diagnosis and treatment plan for new coronavirus infection" in China[18], which includes normal temperature for more than 3 days, both the respiratory symptoms and chest imaging showing significant improvement, and negative two consecutive respiratory pathogen nucleic acid tests with the interval at least 1 day. This study had ethics approval of the Ethics Commission of Wuhan Jin Yin-tan hospital and Wuhan Union hospital. All participants remained anonymous, and written informed content was waived by ethics commission for rapid emerging infectious diseases.

\section{Clinical Data Collection}

We reviewed the electronic medical records, nursing records, laboratory findings, and radiology findings in all patients. All data were independently reviewed and checked by four physicians (J.L., Y.L., X.H., Y.C.). We collected age, sex, exposure history, underlying disease, maximum body temperature, vital signs, onset of symptoms, and the laboratory finding at admission (complete blood count, liver and kidney function, coagulation profile, C-reactive protein, erythrocyte sedimentation rate, blood gas analysis etc.) and treatment measures [oxygen therapy, antiviral agents, antibacterial agents, corticosteroids, 
immunoglobulin, tracheal intubation and extracorporeal membrane oxygenation(ECMO)]. In addition, the durations from onset of disease to hospital admission, chest HRCT scan, ARDS and ICU admission were recorded. ARDS was diagnosed according to the Berlin definition[19].

\section{HRCT image acquisition}

All patients underwent HRCT examination in the supine position on one of the three CT scanners: SOMATOM Definition AS+, SOMATOM Perspective, or SOMATOM Spirit (Siemens Healthineers, Germany). Scans were done from the thoracic inlet to the diaphragm, and no contrast medium was used. CT scan parameters were as described in our previous study[20]. All images were reconstructed using standard reconstruction algorithms with a slice thickness of $2 \mathrm{~mm}$ or $5 \mathrm{~mm}$. The multiplanar reconstruction postprocessing was implemented on workstation and picture archiving and communication systems.

\section{HRCT Image Interpretation}

All HRCT images were reviewed in random order by three radiologists (H.S., J.G., Y.F.) who were senior cardiothoracic radiologists. The readers independently assessed the CT features using both axial and MPR images, who were unaware of any other clinical and laboratory findings or outcome of the patients. After independent evaluation, discussion and consensus resolved the disagreements.

For each severe pneumonia patients, the predominant HRCT patterns defined by the Fleischner Society glossary[21] were as following: ground-glass opacities (GGO), consolidation, interlobular septal thickening, crazy-paving pattern, air bronchogram, pneumonectasis, pleural effusion and pneumomediastinum. The distribution of lesion was categorized as diffuse central area and peripheral area.

To quantify the extent of pulmonary abnormalities, a HRCT score system[22] was assigned on the basis of the area involved. And a previous study[23] has demonstrated that this system was correlated well with the degree of pulmonary lesions in pathologic specimens. Specifically, each of the five lung lobes was visually scored from 0 to 5 as: 0 , no involvement; $1 .<5 \%$ of lobe (minimal but not normal), 2 . $5 \%-25 \%$ of lobe, $3.26 \%-49 \%$ of lobe; $4.50 \%-75 \%$ of lobe; $5 .>75 \%$ of lobe. Finally, the total CT severity score was calculated by summing the individual lobar scores (range of possible scores from 0 to 25 ).

\section{Statistical Analysis}

The Kolmogorov-Smirnov test was used to checked the normality of all continuous data. Normally and non-normally distributed data and categorical variables are expressed as the mean (SD) and the medians(IQR) and number (\%), respectively. We assessed differences between two groups of normally distributed variables using two-sample t test or Mann-Whitney $U$ test depending on normally and nonnormally distributed data for continuous variables and Fisher's exact test for categorical variables. The association between baseline clinical or HRCT Findings and incidence of death events was assessed with univariate logistic regression model (P凶0.1 in Table 1-3). From a clinical point of view, to ensure proper 
independent variable number and avoid variable overfitting of the final multivariable model, we implemented the following step:1) first, a multivariable model (Model 1: baseline characteristics) was tested, including those baseline variables that showed an association $(p<0.1$ in Table 4) with incidence of death events. 2) a second multivariable model (Model 2: laboratory findings) was tested, including those baseline laboratory findings that showed an association $(p<0.1$ in Table 4$)$ with incidence of death events. 3) a third multivariable model (Model 3: HRCT findings) was tested, including those baseline HRCT findings that showed an association ( $p<0.1$ in Table 4) with incidence of death events. 4) a final multivariable model (Model 4: baseline characteristics plus laboratory findings plus HRCT findings) included variables from Model 1-3 that were independently related to the incidence of death events. The minimum sample size of the study should be 10 times greater than the included independent variable number. Co-linearity of variables tested in multivariate regression model (table 4) was evaluated using the tolerance statistic and the variance inflation factor (excessive if $<0.1$ and if $>10$, respectively). Statistical significance was considered a p value $<0.05$ (2-tailed). Analyses were conducted using SPSS software (SPSS 21.0 for Windows, IBM, Chicago, IL, USA).

\section{Results}

\section{Demographics and baseline characteristics in severe COVID-19 patients}

Between January 5, 2020, to Feb 22, 2020, 101 patients (87 from Jin Yin-tan hospital, 14 from Wuhan Union hospital) with severe COVID-19 who underwent chest CT scans on admission were included in this study. According to hospital data, of 87 patients from Jin Yin-tan hospital, 16 have been described by Wu et al[11] and Zhou et al[12].

Of all patients with severe COVID-19, 66 patients $(65.3 \%)$ have recovered from severe pneumonia and were discharged from hospital, 35 cases (34.7\%) died despite supportive treatment. As Table 1 showed, the mean age was $56.6 \pm 15.1$ years (ranged from 23 to 82 years old). $67(66.3 \%)$ were male, $15(14.9 \%)$ had direct exposure to the Huanan seafood market, 8 cases $(7.9 \%)$ were familial clusters. The most common symptom at onset were fever $(96,95.0 \%)$ and cough $(79,78.2 \%)$. Of the 101 patients, the most common coexisting conditions was hypertension $(38,37.6 \%)$, followed by cardiovascular disease, diabetes and chronic pulmonary disease. In addition, 14 (13.9\%) patients were complicated with bacterial infection.

The mean duration from onset of symptoms to hospital admission, ARDS and ICU admission were $11.2 \pm 5.5$ days, $15.0 \pm 6.6$ days, and $15.4 \pm 5.4$ days, respectively. The mean hospital day and duration of disease were $15.6 \pm 8.1$ days and $26.6 \pm 8.5$ days, respectively. The mean duration from onset of symptoms to ICU admission was significantly longer in deceased patients than discharged patients ( $p \varangle 0.05)$. The hospital day and duration of disease were significantly longer in discharged patients than deceased groups ( $p \otimes 0.05)$ (Table 1).

Compared with discharged patients, deceased patients were significantly older and were more likely to have ARDS and comorbidities, including cardiovascular disease, diabetes, hypertension, and chronic 
pulmonary disease ( $p \bowtie 0.05)$ (Table 1$)$.

All patients were treated oxygen therapy (100\%). 93 (92.1\%) patients received antibacterial treatment, 88 (87.1\%) patients received antiviral treatment, 49 (50\%) received glucocorticosteroids, $45(86.5 \%)$ received immunoglobulin, $22(21.8 \%)$ received tracheal intubation, and 4 (4.1\%) patients received extracorporeal membrane oxygenation (ECMO). Compared with discharged patients, deceased patients were more likely to receive glucocorticosteroids, immunoglobulin, tracheal intubation and ECMO (Table 1).

The mean survival time in the death group from disease onset to death were $22.6 \pm 7.2$ days. Among the 35 severe deceased cases, 21 patients $(60 \%)$ died of respiratory failure, 4 patients $(11.4 \%)$ with myocardial damage died of circulatory failure, 8 patients $(22.9 \%)$ died of respiratory and circulatory failure, and 2 (5.7\%) with severe sepsis died of multiple organ failure (Figure 1).

\section{Baseline laboratory findings in severe COVID-19 patients}

The laboratory findings showed lymphocytopenia in 62 (82.7\%) patients on admission. 54 (68.4\%) patients were noted to have elevated alanine transaminase (ALT), $49(64.5 \%)$ had elevated aspartate aminotransferase(AST), 77 (96.3\%) had elevated lactate dehydrogenase (LDH), 56 (87.5\%) patients had elevated D-dimer, 45 (84.9\%) had elevated hypersensitive troponin I, and 31 (57.4\%) had elevated myoglobin. The levels of hyper-sensitive C-reactive protein, Serum amyloid A protein, and erythrocyte sedimentation rate were markedly increased in almost all patients (Table 2).

The lymphocyte count, hemoglobin, albumin level on admission and oxygen saturation on room air were significantly lower in deceased patients than discharged patients ( $p \bowtie 0.05)$. Lactate dehydrogenase (LDH), creatinine, D-dimer and hypersensitive troponin I level on admission were higher in deceased patients than discharged patients ( $p \bigotimes 0.05$ ) (Table 2).

\section{Baseline HRCT findings in severe COVID-19 patients}

The median time interval from admission to baseline CT scan in all patients were 4 days (IQR 1,9), with no difference between discharged and deceased patients (Table 3). The typical chest CT findings of severe COVID-19 on admission were diffuse bilateral GGO and consolidation in peripheral areas (Figure 27). GGO $(90,89.1 \%)$ is main diffusion lesion characteristics in all patients, and consolidation proportion (8[22.9] vs $3[4.5], p \varangle 0.005)$ was comparatively higher in deceased patients than discharged patients (Table 3). The mean total CT scores in all patients was 17.4 \pm 5.1 . Deceased patients had higher CT scores than discharged patients (20.9 \pm 3.0 vs $15.6 \pm 5.0, p \llbracket 0.001)$ (Figure1).

The other common CT findings were interlobular septal thickening $(72 / 101,71.3 \%)$, crazy paving $(48 / 101$, $47.5 \%)$ and air bronchograms $(75 / 101,74.3 \%)$. The relatively less common CT findings were pleural effusion $(28 / 101,28 \%)$, emphysema $(15 / 101,14.9 \%)$, hydropericardium $(10 / 101,9.9 \%)$ and pneumomediastinum (3/101, 3.0\%) (Table 3$)$. 
Interlobular septal thickening, crazy-paving, air bronchogram, and pleural were significantly more common in deceased patients than discharged patients ( $p \varangle 0.05)$ (Table 3).

\section{Univariate and multivariable analysis of predictors of mortality risk}

By univariate regression analysis in severe COVID-19 patients, the following baseline characteristics were predictors of mortality risk: older age, faster respiratory rate, ARDS, history of diabetes, history of hypertension; the following laboratory findings were predictors of mortality risk: reduced lymphocyte count, reduced albumin, elevated lactate dehydrogenase, elevated D-dimer, reduced SpO2 at room air; the following baseline HRCT findings were predictors of mortality risk: elevated total HRCT score, higher consolidation proportion, pleural effusion (Table 4).

The multivariable regression analysis showed older age (OR:1.142, 95\% Cl:1.059-1.231, p囚0.001), ARDS (OR:10.142, 95\% Cl:1.611-63.853, $p=0.014$ ), reduced lymphocyte count (OR:0.004, 95\% Cl: 0.001-0.306, $p=0.013)$, and elevated HRCT score (OR:1.276, 95\% Cl:1.002-1.625, $p=0.049)$ independent predictors of mortality risk on admission in severe COVID-19 patients (Table 4).

\section{Discussion}

To our knowledge, this is the first study to investigate the prognostic value of baseline clinical and HRCT findings in severe patients with COVID-19. In two previously published prognostic studies[11, 12], included groups were not all severe patients and HRCT findings associated with poor clinical outcomes have not been delineated. The main finding of our study was that older age, developed ARDS, lymphocytopenia, and high CT score were the independent predictors of mortality risk in severe patients with COVID-19.

In our study, the mean age of severe patients with COVID-19 was $56.6 \pm 15.1$ years old, and more than $60 \%$ of patients were men. As described in previous studies[2, 3, 9, 10], elderly male patients are more susceptible to SARS-CoV-2 infection, which were supported by our severe patient cohort. But there was no sexual distinction between deceased and discharged patients in our study, which indicated gender is not a risk factor of death. In concert with a recent study[10], we observed that deceased group was significantly older than the discharged group in severe COVID-19. And in the multivariable regression analysis, we have demonstrated the older age was an independent predictor of mortality risk in severe COVID-19 patients. Therefore, the clinical imperatively management for severe elderly patients requires further attention. Fever is the most common clinical symptom in severe patients with COVID-19, but $5 \%$ patients had no fever at the onset of disease, which is also in line with previous studies[8, 24]. If patients are asymptomatic SARS-CoV-2 carriers, early diagnosis is relatively difficult for areas with less medical specialties [25]. Absence of typical initial symptoms for few patients may delay the optimal quarantine and treatment time and lead to poor outcome. However, in our present study, no significant differences were found between the initial symptoms of deceased patients and discharged patients.

ARDS characterized by an acute, diffuse, inflammatory lung damage is one of the most common causes of respiratory failure in critically ill patients with viral pneumonia[26]. In our study, compared with 
discharged patients with severe COVID-19, the deceased group has significantly higher incidence of ARDS. ARDS was an independent predictor of mortality risk in severe COVID-19 patients, which is similar to critically ill patients with SARS[27]. The incidence of ARDS in the present study is consistent with previous critically ill patients with COVID-19[10], but which is slightly higher than that previously seen in patients with SARS[27, 28] and MERS[29]. Such a discrepancy may be due to failure to timely diagnosis and treatment in the situation of sudden increase in infected patients. Of note, the incidence of ARDS of survivors in the present study is significantly higher than that recently reported in Zhou's study[12]. The different inclusion criteria, our discharged group were all severe patients, may result in the problem. In future, the earlier recognition of ARDS and ongoing efforts to study potential mechanisms of pulmonary damage in severe COVID-19 are the keys to reduce mortality rate. In addition, hypertension, cardiovascular disease and diabetes are the most common comorbidities in severe patients, which is in keep with previous studies[9, 10]. Similarly, deceased patients had more comorbidities, such as hypertension, diabetes, and chronic pulmonary disease, than those discharged. Although comorbidities were not risk factors for death event in multivariable regression analysis, clinicians still require to focus on the clinical progression in severe patients.

In terms of laboratory indexes, more than $80 \%$ of severe patients in the present study have lymphocytopenia on admission, and the lymphocyte count was significantly lower in deceased patients than discharged patients. This finding is similar to previous COVID-19, SARS and MERS patients [10, 30, 31]. Unlike Chen's study showed less than $40 \%$ of non-severe patients had only mild lymphocytopenia, the present study indicated the extent of lymphocytopenia may reflect the severity of SARS-CoV-2 infection. Furthermore, our study first demonstrated lymphocytopenia is an independent predictor of mortality risk in severe patients with COVID-19. Prior studies reported that severe SARS or MERS patients were prone to have lymphocytopenia. It may due to virus particle directly invading and damaging the lymphocyte cytoplasmic component or lymphocytes apoptosis[31, 32]. Unfortunately, the pathogenesis of lymphocytopenia in severe COVID-19 is still unclear by now, later basic immunology may be the key to solve the problem. Additionally, compared with discharged patients, deceased patients had lower hemoglobin and albumin level, higher LDH, Creatinine, D-dimer and hypersensitive troponin I level. These abnormal results suggest that the severity of SARS-CoV-2 infection may be related to coagulation activation, myocardial damage and kidney damage. Unlike a previous study[9], although more than $50 \%$ severe patients have elevated ALT and AST, no significant differences of ALT and AST level were found between deceased and discharged patients with severe COVID-19. Liver damage in patients with COVID19 is common, especially in critically ill patients. The possible reasons are as follows: 1)liver cells are possibly directly infected with virus, 2) drug hepatotoxicity in the treatment, 3)immune-mediated inflammation, such as cytokine storm[33]. Although, liver damage is not a prognostic factor in the present study, further research still should pay close attention to the causes and evolution of liver injury in COVID19.

Of note, the present study showed that elevated baseline HRCT score is an independent prognostic factor of mortality risk in severe COVID-19 patients. CT score[22] was a semi quantitative parameter, which could quantify the severity of pulmonary abnormalities (GGO and consolidation dominated in COVID-19). 
Previous studies $[23,34]$ have demonstrated that the score was correlated with the degree of pulmonary lesions in pathologic specimens. CT score has been applied in the quantitative assessment of the evolution of pulmonary lesions in previous SARS[35] and COVID-19 patients[36].To the best of our knowledge, this is the first study to assess the prognostic value of baseline CT score, which has a significant value for clinical decisions based on radiological risk stratification in severe COVID-19 patients. We have reasons to believe that CT scan after hospital admission may be an important imaging modality in assisting the diagnosis and assessment of outcome in patients with severe COVID-19. However, given the infectious risk of transporting patients with COVID-19 for other hospitalized patients and health care workers, it's necessary to select the appropriate timing for immediate CT imaging. First, in the outbreak stage of COVID-19, RT-PCR for SARS-CoV-2 viral nucleic acid was reported to have a sensitivity of less than $60 \%$ [15]. Based on a higher sensitivity (80-90\%) for COVID-19[15, 37], HRCT can be considered as a primary tool for the current COVID-19 detection in epidemic areas. Second, With the improvement of the accuracy and rapidity of the RT-PCR testing, immediate CT imaging is mainly used for suspected positive patients[38]. Third, for some patients prone to severe COVID-19, CT scan after hospital admission may be an important tool in assisting reasonable risk stratification and timely clinical management.

Like SARS and MERS, the CT findings of severe COVID-19 patients were nonspecific, which included diffusely bilateral GGO and consolidation of subsegmental areas. However, the extent of consolidation in severe COVID-19 patients was less severe than SARS patients[39]. Interestingly, although GGO was mainly diffuse in all patients, the consolidation proportion was comparatively higher in died patients than discharged patients. In a recent autopsy report of a deceased COVID-19 patient, Liu et al[40] demonstrated that edema, inflammatory infiltrate, and exudation were common in affected lung areas. Those may explain the predominant pattern of GGO on CT images. At present, the relation between the extent of consolidation and outcome is unclear, which needs further large sample autopsy and HRCT studies. In this study, 28\% patients with severe COVID-19 had pleural effusion, and which was significantly more common in deceased patients than discharged patients. Due to the present study mainly included severe patients, the incidence of pleural effusion may be higher than previous studies[20, 41]. Das et al 's study[42] showed that the presence of pleural effusion was a poor prognostic factor in patients with MERS. Consequently, severe patients having abnormal pleural effusion deserve the attention of clinicians. All in all, baseline CT may be an important imaging modality in assisting the diagnosis and assessment of outcome in patients with severe COVID-19.

This study has several limitations. First, the sample size was small. Second, this is a retrospective study design, a few of clinical and laboratory results were missing in some patients, which may lead to unavoidable biases in analysis. Third, some survivors still hospitalized were not included the present study, the mortality rate of severe patients was overestimated in this study.

\section{Conclusion}


In conclusion, older age, ARDS, lymphocytopenia and elevated CT score were strong predictors of mortality risk in these severe COVID-19 patients. For some patients prone to severe COVID-19, CT scan after hospital admission may be an important imaging modality in assisting assessment of outcome in patients with severe COVID-19. Our findings may have important implications for clinical decisions based on risk stratification in severe pneumonia patients. As our study was a retrospective design and suffered from selection bias, further prospective studies are needed to sustain our findings.

\section{Abbreviations}

severe acute respiratory syndrome coronavirus 2, SARS-CoV-2; novel coronavirus pneumonia, COVID-19; severe acute respiratory syndrome, SARS; middle east respiratory syndrome, MERS; World Health Organization, WHO; real-time reverse transcription-polymerase-chain-reaction assay, RT-PCR; extracorporeal membrane oxygenation, ECMO; multiplanar reconstruction, MPR; ground-glass opacities, GGO; alanine transaminase, ALT; aspartate aminotransferase, AST; lactate dehydrogenase, LDH.

\section{Declarations}

\section{Ethics approval and consent to participate:}

This study was approved by both ethics committees of Union hospital of Tongji Medical College of Huazhong University of Science and Technology and Wuhan Jin-yintan hospital. written informed content was waived by ethics commission for rapid emerging infectious diseases.

\section{Consent for publication:}

Not Applicable

\section{Availability of data and materials:}

The datasets used and analyzed during the current study are available from the corresponding author on reasonable request

\section{Competing interests:}

All authors declared that: there is no conflict of interest existing in the submission of this manuscript, and all authors approved the article for publication.

\section{Funding:}

This study was supported by Zhejiang University special scientific research fund for COVID-19 prevention and control and the Fundamental Research Funds for the Central Universities(2020kfyXGYJ019). The funders only provide funding and have no influence on study design, data collection, data analysis, data interpretation, decision to publish, or writing the manuscript.

\section{Authors' contributions:}

Conception and design: Yanqing Fan, Hanping Wu, Heshui Shi, Yukun Cao, Xiaoyu Han; Collection and assembly of data: Jin Gu, Xiaoyu Han, Jia Liu,Yumin Li, Yukun Cao, Xin Zhang, Osamah Alwalid; Data 
analysis and interpretation: Jin Gu, Yanqing Fan, Yue Cui, Chuansheng Zheng; Manuscript writing: Yukun Cao, Xiaoyu Han; Final approval of manuscript: All authors; Accountable for all aspects of the work: All authors.

7. Acknowledgements: None

\section{References}

1. Zhu N, Zhang D, Wang W, Li X, Yang B, Song J, Zhao X, Huang B, Shi W, Lu R et al: A Novel Coronavirus from Patients with Pneumonia in China, 2019. N Engl J Med 2020.

2. Huang C, Wang Y, Li X, Ren L, Zhao J, Hu Y, Zhang L, Fan G, Xu J, Gu X et al: Clinical features of patients infected with 2019 novel coronavirus in Wuhan, China. The Lancet 2020.

3. Chen N, Zhou M, Dong X, Qu J, Gong F, Han Y, Qiu Y, Wang J, Liu Y, Wei Y et al: Epidemiological and clinical characteristics of 99 cases of 2019 novel coronavirus pneumonia in Wuhan, China: a descriptive study. The Lancet 2020, 395(10223):507-513.

4. Li Q, Guan X, Wu P, Wang X, Zhou L, Tong Y, Ren R, Leung KSM, Lau EHY, Wong JY et al: Early Transmission Dynamics in Wuhan, China, of Novel Coronavirus-Infected Pneumonia. New England Journal of Medicine 2020.

5. World Health Organization. (2020). Novel Coronavirus (2019-nCoV): situation report, 50. World Health Organization.https://www.who.int/docs/default-source/coronaviruse/situation-reports/20200310sitrep-50-covid-19.pdf?sfvrsn=55e904fb_2 .

6. Yin Y, Wunderink R: MERS, SARS and other coronaviruses as causes of pneumonia: MERS, SARS and coronaviruses. Respirology 2017, 23.

7. Zaki AM, van Boheemen S, Bestebroer TM, Osterhaus ADME, Fouchier RAM: Isolation of a Novel Coronavirus from a Man with Pneumonia in Saudi Arabia. New England Journal of Medicine, 367(19):1814-1820.

8. Xu X-W, Wu X-X, Jiang X-G, Xu K-J, Ying L-J, Ma C-L, Li S-B, Wang H-Y, Zhang S, Gao H-N et al: Clinical findings in a group of patients infected with the 2019 novel coronavirus (SARS-Cov-2) outside of Wuhan, China: retrospective case series. Bmj 2020:m606.

9. Wang D, Hu B, Hu C, Zhu F, Liu X, Zhang J, Wang B, Xiang H, Cheng Z, Xiong Y et al: Clinical Characteristics of 138 Hospitalized Patients With 2019 Novel Coronavirus-Infected Pneumonia in Wuhan, China. JAMA 2020.

10. Yang X, Yu Y, Xu J, Shu H, Xia Ja, Liu H, Wu Y, Zhang L, Yu Z, Fang M et al: Clinical course and outcomes of critically ill patients with SARS-CoV-2 pneumonia in Wuhan, China: a singlecentered, retrospective, observational study. The Lancet Respiratory Medicine 2020.

11. Wu C, Chen X, Cai Y, Xia J, Zhou X, Xu S, Huang H, Zhang L, Zhou X, Du C et al: Risk Factors Associated With Acute Respiratory Distress Syndrome and Death in Patients With Coronavirus Disease 2019 Pneumonia in Wuhan, China. JAMA Intern Med 2020. 
12. Zhou F, Yu T, Du R, Fan G, Liu Y, Liu Z, Xiang J, Wang Y, Song B, Gu X et al: Clinical course and risk factors for mortality of adult inpatients with COVID-19 in Wuhan, China: a retrospective cohort study. The Lancet 2020.

13. Guo L, Wei D, Zhang X, Wu Y, Li Q, Zhou M, Qu J: Clinical Features Predicting Mortality Risk in Patients With Viral Pneumonia: The MuLBSTA Score. Front Microbiol 2019, 10:2752.

14. Lee EYP, Ng M-Y, Khong P-L: COVID-19 pneumonia: what has CT taught us? The Lancet Infectious Diseases.

15. Ai T, Yang Z, Hou H, Zhan C, Chen C, Lv W, Tao Q, Sun Z, Xia L: Correlation of Chest CT and RT-PCR Testing in Coronavirus Disease 2019 (COVID-19) in China: A Report of 1014 Cases. Radiology 2020, 0(0):200642.

16. World Health Organization. Clinical management of severe acute respiratory infection when novel coronavirus (nCoV) infection is suspected: interim guidance. Published January 28,2020 . Accessed January 31, 2020. https://www.who.int/publications-detail/clinical-management- of-severe-acuterespiratory infection-when-novel-coronavirus-(ncov)-infection-is-suspected

17. World Health Organization. Clinical management of severe acute respiratory infection when novel coronavirus (nCoV) infection is suspected: interim guidance. https://www.who.int/docs/defaultsource/coronaviruse/clinical-management-of-novel-cov.pdf Published on January 12, 2020.

18. General Office of National Health Committee. Notice on the issuance of a program for the diagnosis and treatment of novel coronavirus (2019-nCoV) infected pneumonia (trial sixth edition) 2020.2.18http://www.nhc.gov.cn/yzygj/s7653p/202002/8334a8326dd94d329df351d7da8aefc2 .shtml?from=timeline (accessed Feb 24, 2020)

19. Force ADT, Ranieri VM, Rubenfeld GD, Thompson BT, Ferguson ND, Caldwell E, Fan E, Camporota L, Slutsky AS: Acute respiratory distress syndrome: the Berlin Definition. JAMA 2012, 307(23):25262533.

20. Shi H, Han X, Jiang N, Cao Y, Alwalid O, Gu J, Fan Y, Zheng C: Radiological findings from 81 patients with COVID-19 pneumonia in Wuhan, China: a descriptive study. The Lancet Infectious Diseases 2020.

21. Hansell DM, Bankier AA, MacMahon H, McLoud TC, Müller NL, Remy J: Fleischner Society: Glossary of Terms for Thoracic Imaging. Radiology 2008, 246(3):697-722.

22. Chang Y-C, Yu C-J, Chang S-C, Galvin JR, Liu H-M, Hsiao C-H, Kuo P-H, Chen K-Y, Franks TJ, Huang K$M$ et al: Pulmonary Sequelae in Convalescent Patients after Severe Acute Respiratory Syndrome: Evaluation with Thin-Section CT. Radiology 2005, 236(3):1067-1075.

23. Kazerooni EA, Martinez FJ, Flint A, Jamadar DA, Gross BH, Spizarny DL, Cascade PN, Whyte RI, Lynch JP, Toews G: Thin-section CT obtained at 10-mm increments versus limited three-level thin-section CT for idiopathic pulmonary fibrosis: correlation with pathologic scoring. 1997, 169(4):977-983.

24. Guan WJ, Ni ZY, Hu Y, Liang WH, Ou CQ, He JX, Liu L, Shan H, Lei CL, Hui DSC et al: Clinical Characteristics of Coronavirus Disease 2019 in China. N Engl J Med 2020. 
25. Zhu N, Zhang D, Wang W, Li X, Yang B, Song J, Zhao X, Huang B, Shi W, Lu R et al: A Novel Coronavirus from Patients with Pneumonia in China, 2019. N Engl J Med 2020, 382(8):727-733.

26. Matthay MA, Zemans RL, Zimmerman GA, Arabi YM, Beitler JR, Mercat A, Herridge M, Randolph AG, Calfee CS: Acute respiratory distress syndrome. Nature Reviews Disease Primers 2019, 5(1):18.

27. Lew TW, Kwek TK, Tai D, Earnest A, Loo S, Singh K, Kwan KM, Chan Y, Yim CF, Bek SL et al: Acute respiratory distress syndrome in critically ill patients with severe acute respiratory syndrome. JAMA 2003, 290(3):374-380.

28. Gomersall CD, Joynt GM, Lam P, Li T, Yap F, Lam D, Buckley TA, Sung JJ, Hui DS, Antonio GE et al: Short-term outcome of critically ill patients with severe acute respiratory syndrome. Intensive Care Med 2004, 30(3):381-387.

29. Arabi YM, Arifi AA, Balkhy HH, Najm H, Aldawood AS, Ghabashi A, Hawa H, Alothman A, Khaldi A, Al Raiy B: Clinical course and outcomes of critically ill patients with Middle East respiratory syndrome coronavirus infection. Ann Intern Med 2014, 160(6):389-397.

30. Chu H, Zhou J, Ho-Yin WB, Li C, Fuk-Woo CJ, Zhong-Shan C, Yang D, Wang D, Chak-Yiu LA, Li C: Middle East Respiratory Syndrome Coronavirus Efficiently Infects Human Primary T Lymphocytes and Activates the Extrinsic and Intrinsic Apoptosis Pathways. Journal of Infectious Diseases 2015(6):6.

31. Liu, Kefang, Tan, Wenjie, Xu, Kun, Wong, Gary, Gao, George: T-cell immunity of SARS-CoV: Implications for vaccine development against MERS-CoV.

32. Gu, J.: Multiple organ infection and the pathogenesis of SARS. Journal of Experimental Medicine, 202(3):415-424.

33. Zhang C, Shi L, Wang F-S: Liver injury in COVID-19: management and challenges. The Lancet Gastroenterology \& Hepatology.

34. Flaherty KR, Colby TV, Travis WD, Toews GB, Mumford J, Murray S, Thannickal VJ, Kazerooni EA, Gross BH, Lynch JP et al: Fibroblastic foci in usual interstitial pneumonia: idiopathic versus collagen vascular disease. American journal of respiratory and critical care medicine 2003, 167(10):14101415.

35. Ooi GC, Khong PL, Müller NL, Yiu WC, Zhou LJ, Ho JCM, Lam B, Nicolaou S, Tsang KWT: Severe Acute Respiratory Syndrome: Temporal Lung Changes at Thin-Section CT in 30 Patients1. Radiology, 230(3):836-844.

36. Pan F, Ye T, Sun P, Gui S, Liang B, Li L, Zheng D, Wang J, Hesketh RL, Yang L et al: Time Course of Lung Changes On Chest CT During Recovery From 2019 Novel Coronavirus (COVID-19) Pneumonia. Radiology 2020:200370.

37. Bai HX, Hsieh B, Xiong Z, Halsey K, Choi JW, Tran TML, Pan I, Shi L-B, Wang D-C, Mei J et al: Performance of radiologists in differentiating COVID-19 from viral pneumonia on chest CT. Radiology 2020:200823.

38. Mossa-Basha M, Meltzer CC, Kim DC, Tuite MJ, Kolli KP, Tan BS: Radiology Department Preparedness for COVID-19: Radiology Scientific Expert Panel. Radiology 2020:200988. 
39. Wong KT, Antonio GE, Hui DSC, Lee N, Yuen EHY, Wu A, Leung CB, Rainer TH, Cameron P, Chung SSC et al: Severe Acute Respiratory Syndrome: Radiographic Appearances and Pattern of Progression in 138 Patients. Radiology 2003, 228(2):401-406.

40. Q L, R W, G Q, Wang Y: Autopsy report in a dead patient with COVID-19. Journal of Forensic Medicine 2020, 36(1).

41. Bernheim A, Mei X, Huang M, Yang Y, Fayad ZA, Zhang N, Diao K, Lin B, Zhu X, Li K et al: Chest CT Findings in Coronavirus Disease-19 (COVID-19): Relationship to Duration of Infection. Radiology 2020, 0(0):200463.

42. Das KM, Lee EY, Enani MA, AlJawder SE, Singh R, Bashir S, Al-Nakshbandi N, AlDossari K, Larsson SG: CT Correlation With Outcomes in 15 Patients With Acute Middle East Respiratory Syndrome Coronavirus. Ajr American Journal of Roentgenology, 204(4):736-742.

\section{Tables}

Table 1 Demographics and baseline characteristics of patients with severe COVID-19 


\begin{tabular}{|c|c|c|c|c|}
\hline & $\begin{array}{c}\text { All patients } \\
(\mathrm{n}=101)\end{array}$ & $\begin{array}{l}\text { Survivors } \\
(\mathrm{n}=66)\end{array}$ & $\begin{array}{c}\text { Non-survivors } \\
(\mathrm{n}=35)\end{array}$ & $P$ value \\
\hline Age, years & $56.6 \pm 15.1$ & $51.1 \pm 14.2$ & $66.8 \pm 10.9$ & $\square 0.001^{*}$ \\
\hline Sex & & & & 0.430 \\
\hline Female & $34(33.7)$ & $24(36.4)$ & $10(28.6)$ & \\
\hline Male & $67(66.3)$ & $42(63.6)$ & $25(71.4)$ & \\
\hline Huanan Seafood Market exposure & 15(14.9) & $12(25.0)$ & $3(11.5)$ & 0.217 \\
\hline Maximum temperature $\left({ }^{\circ} \mathrm{C}\right)$ & $38.7 \pm 0.8$ & $38.6 \pm 0.7$ & $38.7 \pm 1.0$ & 0.799 \\
\hline Heart rate (bmp) & $91.7 \pm 13.0$ & $91.2 \pm 12.4$ & $92.5 \pm 14.0$ & 0.639 \\
\hline Respiratory rate & $23.2 \pm 4.9$ & $22.4 \pm 4.0$ & $24.6 \pm 5.7$ & $0.033^{*}$ \\
\hline $\mathrm{SBP}(\mathrm{mmHg})$ & $131.0 \pm 20.0$ & $131.7 \pm 18.4$ & $129.9 \pm 23.3$ & 0.677 \\
\hline DBP (mmHg) & $80.1 \pm 12.1$ & $81.0 \pm 11.0$ & $78.5 \pm 13.3$ & 0.326 \\
\hline \multicolumn{5}{|l|}{ Signs and symptoms } \\
\hline Fever & 96(95.0) & $62(93.9)$ & $34(97.1)$ & 0.656 \\
\hline Fatigue & $49(48.5)$ & $29(43.9)$ & $20(57.1)$ & 0.206 \\
\hline Cough & $79(78.2)$ & $53(80.3)$ & $26(74.3)$ & 0.486 \\
\hline Expectoration & $48(47.5)$ & $31(47.0)$ & $17(48.6)$ & 0.878 \\
\hline Dyspnea & 17(16.8) & $8(12.1)$ & $9(25.7)$ & 0.082 \\
\hline Myalgia & 13(12.9) & $8(12.1)$ & $5(14.3)$ & 0.757 \\
\hline Abdominal pain & $2(2.0)$ & $0(0)$ & $2(5.7)$ & 0.118 \\
\hline Diarrhea & $9(8.9)$ & $6(9.1)$ & $3(8.6)$ & 1.000 \\
\hline Dizziness & 11(10.9) & $9(13.6)$ & $2(5.7)$ & 0.321 \\
\hline Nausea & $9(8.9)$ & $4(6.2)$ & $5(14.3)$ & 0.271 \\
\hline Vomiting & $7(6.9)$ & $4(6.2)$ & $3(8.6)$ & 0.693 \\
\hline \multicolumn{5}{|l|}{ Comorbidities } \\
\hline Cardiovascular disease & $21(20.8)$ & $10(15.2)$ & $11(31.4)$ & 0.055 \\
\hline Diabetes & $18(17.8)$ & $6(9.1)$ & $12(34.3)$ & $0.002 *$ \\
\hline Hypertension & $38(37.6)$ & $20(30.3)$ & $18(51.4)$ & $0.037 *$ \\
\hline Chronic pulmonary disease & $16(15.8)$ & $9(25.7)$ & $7(10.6)$ & $0.048^{*}$ \\
\hline Chronic liver disease & $5(5.0)$ & $2(3.0)$ & $3(8.6)$ & 0.338 \\
\hline Malignancy & $5(5.0)$ & $3(4.5)$ & $2(5.7)$ & 0.797 \\
\hline Bacterial infection & $14(13.9)$ & $8(22.9)$ & $6(9.1)$ & 0.057 \\
\hline Acute respiratory distress syndrome & $44(43.6 \%)$ & $16(24.2 \%)$ & $28(80 \%)$ & $\square 0.001 *$ \\
\hline \multicolumn{5}{|c|}{ Time interval from onset of symptom (days) } \\
\hline Hospital admission & $11.2 \pm 5.5$ & $11.2 \pm 5.5$ & $11.3 \pm 5.5$ & 0.907 \\
\hline Acute respiratory distress syndrome & $15.0 \pm 6.6$ & $11.9 \pm 5.8$ & $16.7 \pm 6.4$ & $0.019 *$ \\
\hline ICU admission & $15.4 \pm 5.4$ & $11.9 \pm 5.5$ & $17.7 \pm 5.1$ & $\square 0.001 *$ \\
\hline hospital day (days) & $15.6 \pm 8.1$ & $17.1 \pm 8.2$ & $12.7 \pm 7$ & $0.008 *$ \\
\hline Duration of disease (days) & $26.6 \pm 8.5$ & $28.3 \pm 8.8$ & $23.4 \pm 7.1$ & $0.006^{*}$ \\
\hline \multicolumn{5}{|l|}{ Treatment } \\
\hline Oxygen therapy & $101(100)$ & $66(100)$ & $35(100)$ & - \\
\hline Antiviral agents & $88(87.1)$ & $64(97.0)$ & $24(68.6)$ & $\square 0.001 *$ \\
\hline Antibacterial agents & 93(92.1) & $60(90.9)$ & $33(94.3)$ & 0.550 \\
\hline Glucocorticoids & $49(50)$ & $28(42.4)$ & $21(65.6)$ & $0.031 *$ \\
\hline Immunoglobulin & $45(86.5)$ & $10(58.8)$ & $35(100)$ & $\square 0.001 *$ \\
\hline Tracheal intubation & $22(21.8)$ & $1(1.5)$ & $21(60.0)$ & $\square 0.001^{*}$ \\
\hline ECMO & $4(4.1)$ & $0(0)$ & $4(12.5)$ & $0.004^{*}$ \\
\hline
\end{tabular}

Data are mean (SD) or $\mathrm{n}(\%)$. p values comparing survivors and non-survivors are from $\chi \square$, Fisher's exact test and independent-samples $\mathrm{T}$ test. SBP, systolic blood pressure, DBP, diastolic blood pressure; ICU, intensive care unit; ECMO, extracorporeal membrane oxygenation. * p $\square 0.05$ 


\begin{tabular}{|c|c|c|c|c|c|}
\hline & $\begin{array}{l}\text { All patients } \\
(\mathrm{n}=101)\end{array}$ & $\begin{array}{l}\text { Survivors } \\
\qquad(\mathrm{n}=66)\end{array}$ & $\begin{array}{c}\text { Non-survivors } \\
(\mathrm{n}=35)\end{array}$ & Normal range & $\mathrm{P}$ value \\
\hline socyte count $\left(10^{9} / \mathrm{L}\right)$ & $7.6 \pm 3.9$ & $7.6 \pm 3.9$ & $7.5 \pm 4.0$ & $4.0 \sim 10.0$ & 0.971 \\
\hline trophil Count $\left(10^{9} / \mathrm{L}\right)$ & $7.2 \pm 3.7$ & $7.3 \pm 3.8$ & $7.0 \pm 3.6$ & $1.8 \sim 6.3$ & 0.852 \\
\hline phocyte count $\left(10^{9} / \mathrm{L}\right)$ & $0.70 \pm 0.37$ & $0.85 \pm 0.39$ & $0.49 \pm 0.18$ & $1.1 \sim 3.2$ & $\square 0.001 *$ \\
\hline elet count $\left(10^{9} / \mathrm{L}\right)$ & $164.5 \pm 52.1$ & $169.4 \pm 53.2$ & $156.3 \pm 50.2$ & $125.0 \sim 350.0$ & 0.333 \\
\hline 1oglobin $(\mathrm{g} / \mathrm{L})$ & $120.4 \pm 18.5$ & $123.7 \pm 16.6$ & $114.8 \pm 20.5$ & $130.0 \sim 175.0$ & $0.046^{*}$ \\
\hline er-sensitive C-reactive protein (mg/L) & $67.3(24.0,133.9)$ & $54.3(16.0,129.6)$ & $90.4(45.1,141.0)$ & $\square 25.0$ & 0.057 \\
\hline Im amyloid A protein (mg/L) & $174.3 \pm 86.6$ & $165.0 \pm 94.5$ & $193.9 \pm 64.0$ & $\square 10.0$ & 0.170 \\
\hline hrocyte sedimentation rate $(\mathrm{mm} / \mathrm{h})$ & $53.0 \pm 25.1$ & $52.3 \pm 23.4$ & $54.3 \pm 28.1$ & $0 \sim 15.0$ & 0.738 \\
\hline rleukin-6 $(\mathrm{pg} / \mathrm{ml})$ & $11.6 \pm 9.4$ & $10.9 \pm 9.9$ & $12.9 \pm 8.5$ & $0.1 \sim 2.9$ & 0.407 \\
\hline$(\mathrm{U} / \mathrm{L})$ & $54.3 \pm 33.3$ & $57.4 \pm 33.3$ & $49.2 \pm 33.4$ & $5.0 \sim 40.0$ & 0.310 \\
\hline$(\mathrm{U} / \mathrm{L})$ & $58.8 \pm 36.9$ & $56.6 \pm 33.6$ & $62.5 \pm 42.0$ & $8.0 \sim 40.0$ & 0.501 \\
\hline $\min (g / L)$ & $31.0 \pm 4.4$ & $32.2 \pm 4.0$ & $28.3 \pm 4.2$ & $35.0 \sim 55.0$ & $\square 0.001 *$ \\
\hline ate dehydrogenase (U/L) & $476.3 \pm 243.4$ & $402.9 \pm 163.8$ & $583.8 \pm 299.9$ & $109.0 \sim 254.0$ & $0.001 *$ \\
\hline :ose (mmol/L) & $8.5 \pm 5.0$ & $8.3 \pm 5.7$ & $8.7 \pm 3.8$ & $3.9 \sim 6.1$ & 0.718 \\
\hline atinine (umol/L) & $80.0(66.5,99.8)$ & $75.0(65.2,83.6)$ & $93.0(74.2,125.3)$ & $44.0 \sim 133.0$ & $0.017 *$ \\
\hline hrombin time (s) & $16.8(16.2,21.1)$ & $16.8(16.2,23.1)$ & $17.7(16.1,20.7)$ & $11.0 \sim 16.0$ & 0.691 \\
\hline vated partial thromboplastin time(s) & $26.1 \pm 8.9$ & $24.5 \pm 8.3$ & $28.3 \pm 9.4$ & $28.0 \sim 43.5$ & 0.189 \\
\hline smbin time (s) & $19.0 \pm 7.2$ & $18.2 \pm 5.7$ & $20.0 \pm 9.7$ & $14.0 \sim 21.0$ & 0.463 \\
\hline $\operatorname{mer}(\mathrm{mg} / \mathrm{L})$ & $3.09(0.8,7.1)$ & $1.5(0.6,3.1)$ & $7.0(3.3,28.0)$ & $\square 0.5$ & $\square 0.001 *$ \\
\hline ersensitive troponin $\mathrm{I}(\mathrm{pg} / \mathrm{mL})$ & $15.3(3.4,37.7)$ & $3.6(0.3,18.9)$ & $31.4(11.0,94.2)$ & $\square 0.6$ & $\square 0.001 *$ \\
\hline globin $(\mathrm{ug} / \mathrm{L})$ & $118.3(54.3,189.2)$ & $65.5(38.7,183.3)$ & $141.3(59.3,194.8)$ & $50.0 \sim 85.0$ & 0.141 \\
\hline \multirow[t]{2}{*}{ gen saturation on room air (\%) } & $87.7 \pm 9.7$ & $90.7 \pm 8.5$ & $84.1 \pm 9.9$ & $95.0 \sim 99.0$ & $0.005^{*}$ \\
\hline & $7.5 \pm 0.1$ & $7.5 \pm 0.05$ & $7.4 \pm 0.1$ & $7.35 \sim 7.45$ & 0.168 \\
\hline$(\mathrm{mmHg})$ & $70.6 \pm 18.2$ & $71.6 \pm 20.9$ & $69.3 \pm 14.2$ & $80 \sim 100$ & 0.665 \\
\hline $\mathrm{I}_{2}(\mathrm{mmHg})$ & $35.7 \pm 11.8$ & $36.4 \pm 12.4$ & $34.7 \pm 11.2$ & $35 \sim 45$ & 0.638 \\
\hline
\end{tabular}

Data are median (IQR), mean (SD) or n (\%). p values comparing Non-survivors and survivors are from $\chi \square$, Fisher's exact test, independent-samples $\mathrm{T}$ test or Mann-Whitney U test. ALT, alanine transaminase AST, aspartate aminotransferase. * pø0.05.

Table 3 baseline HRCT findings of patients with severe COVID-19 


\begin{tabular}{|c|c|c|c|c|}
\hline & $\begin{array}{l}\text { All patients } \\
(\mathrm{n}=101)\end{array}$ & $\begin{array}{l}\text { survivors } \\
(\mathrm{n}=66)\end{array}$ & $\begin{array}{c}\text { Non-survivors } \\
(\mathrm{n}=35)\end{array}$ & $P$ value \\
\hline $\begin{array}{l}\text { Time from admission to CT scan, days } \\
\text { HRCT score }\end{array}$ & $4(1-9)$ & $4(1-9)$ & $5(3-9)$ & $\begin{array}{c}0.436 \\
-\end{array}$ \\
\hline Left upper lobe & $3.4 \pm 1.3$ & $3.0 \pm 1.4$ & $4.1 \pm 1.0$ & $\square 0.001 *$ \\
\hline Left lower lobe & $3.7 \pm 1.2$ & $3.4 \pm 1.3$ & $4.2 \pm 1.0$ & $0.001 *$ \\
\hline Right upper lobe & $3.5 \pm 1.5$ & $3.1 \pm 1.4$ & $4.4 \pm 1.2$ & $\square 0.001 *$ \\
\hline Right middle lobe & $3.0 \pm 1.3$ & $2.6 \pm 1.2$ & $3.8 \pm 1.0$ & $\square 0.001 *$ \\
\hline Right lower lobe & $3.8 \pm 1.1$ & $3.5 \pm 1.2$ & $4.4 \pm 0.9$ & $\square 0.001 *$ \\
\hline Total lesions score & $17.4 \pm 5.1$ & $15.6 \pm 5.0$ & $20.9 \pm 3.0$ & $\square 0.001 *$ \\
\hline Lung involvement & & & & - \\
\hline Unilateral & 0 & 0 & 0 & - \\
\hline Bilateral & $101(100)$ & $66(100)$ & $35(100)$ & - \\
\hline Predominant distribution & & & & - \\
\hline Diffusely septal/subpleural area & $101(100)$ & $66(100)$ & $35(100)$ & - \\
\hline Diffusely central hilar area & 0 & 0 & 0 & - \\
\hline Main lesion component & & & & $0.005^{*}$ \\
\hline GGO & $90(89.1)$ & 63(95.5) & $27(77.1)$ & - \\
\hline Consolidation & $11(10.9)$ & $3(4.5)$ & $8(22.9)$ & - \\
\hline Other typical signs & & & & - \\
\hline Interlobular septal thickening & $72(71.3)$ & $40(60.6)$ & $32(91.4)$ & $0.001 *$ \\
\hline Crazy-paving sign & $48(47.5)$ & $25(37.9)$ & $23(65.7)$ & $0.008^{*}$ \\
\hline $\begin{array}{l}\text { Air bronchogram } \\
\text { Coexisting lesion }\end{array}$ & $75(74.3)$ & $40(60.6)$ & $35(100)$ & $\begin{array}{c}\square 0.001 * \\
-\end{array}$ \\
\hline Pleural effusion & $28(28.0)$ & 11(16.9) & 17(48.6) & $0.001 *$ \\
\hline Emphysema & $15(14.9)$ & $7(10.6)$ & $8(22.9)$ & 0.099 \\
\hline Hydropericardium & $10(9.9)$ & $5(7.6)$ & $5(14.3)$ & 0.283 \\
\hline Pneumomediastinum & $3(3.0)$ & $2(3.0)$ & $1(2.9)$ & 1.000 \\
\hline
\end{tabular}

Data are mean (SD) or $\mathrm{n}(\%)$. p values comparing discharged patients and died patients are from $\chi \square$, Fisher's exact test, or independent-samples $\mathrm{T}$ test. GGO, ground-glass opacities. * p $\square 0.05$

Table 4. Univariate analysis of predictors of mortality risk in patients with severe COVID-19 


\begin{tabular}{|c|c|c|c|}
\hline & Odds Ratio & $95 \% \mathrm{CI}$ & $\mathrm{P}$ value \\
\hline Age & 1.102 & $1.055-1.151$ & $\square 0.001^{*}$ \\
\hline Sex & 1.429 & $0.588-3.473$ & 0.431 \\
\hline Huanan Seafood Market exposure & 0.391 & $0.100-1.538$ & 0.179 \\
\hline Maximum temperature at admission & 1.071 & $0.638-1.796$ & 0.796 \\
\hline Heart rate at admission & 1.008 & $0.976-1.040$ & 0.636 \\
\hline Respiratory rate & 1.095 & $1.001-1.198$ & $0.048^{*}$ \\
\hline SBP & 0.996 & 0.975-1.016 & 0.674 \\
\hline DBP & 0.983 & $0.950-1.017$ & 0.324 \\
\hline Fever & 2.194 & $0.236-20.417$ & 0.490 \\
\hline Fatigue & 1.701 & $0.744-3.891$ & 0.208 \\
\hline Cough & 0.709 & $0.268-1.871$ & 0.487 \\
\hline Expectoration & 1.066 & $0.469-2.422$ & 0.878 \\
\hline Dyspnea & 2.510 & $0.871-7.235$ & 0.089 \\
\hline Myalgia & 1.208 & $0.364-4.016$ & 0.757 \\
\hline Diarrhea & 0.938 & $0.220-4.000$ & 0.931 \\
\hline Dizziness & 0.384 & $0.078-1.884$ & 0.238 \\
\hline Nausea & 2.542 & $0.636-10.159$ & 0.187 \\
\hline Vomiting & 1.430 & $0.301-6.782$ & 0.653 \\
\hline Acute respiratory distress syndrome & 12.500 & $4.592-34.028$ & $\square 0.001 *$ \\
\hline Cardiovascular disease & 2.567 & $0.962-6.844$ & 0.060 \\
\hline Diabetes & 5.217 & $1.752-15.542$ & $0.003^{*}$ \\
\hline Hypertension & 2.435 & $1.046-5.672$ & $0.039 *$ \\
\hline Chronic pulmonary disease & 2.918 & $0.981-8.679$ & 0.054 \\
\hline Chronic liver disease & 3.000 & $0.477-18.867$ & 0.242 \\
\hline Malignancy & 1.273 & 0.203-7.999 & 0.797 \\
\hline Bacterial infection & 2.963 & $0.936-9.375$ & 0.065 \\
\hline Leukocyte count & 0.998 & $0.888-1.121$ & 0.971 \\
\hline Lymphocyte count & 0.003 & $0.000-0.064$ & $\square 0.001 *$ \\
\hline Neutrophil Count & 0.982 & $0.815-1.183$ & 0.847 \\
\hline Platelet count & 0.995 & $0.985-1.005$ & 0.329 \\
\hline Hemoglobin & 0.973 & $0.946-1.000$ & 0.052 \\
\hline Hyper-sensitive C-reactive protein & 1.006 & $0.999-1.013$ & 0.113 \\
\hline Serum amyloid A protein & 1.004 & 0.998-1.010 & 0.171 \\
\hline Erythrocyte sedimentation rate & 1.003 & 0.985-1.022 & 0.734 \\
\hline Interleukin- 6 & 1.023 & 0.969-1.079 & 0.415 \\
\hline ALT & 0.992 & $0.977-1.007$ & 0.307 \\
\hline AST & 1.004 & 0.992-1.017 & 0.498 \\
\hline Albumin & 0.790 & 0.694-0.899 & $\square 0.001 *$ \\
\hline Lactate dehydrogenase & 1.004 & $1.001-1.006$ & $0.004^{*}$ \\
\hline Glucose & 1.018 & $0.926-1.118$ & 0.716 \\
\hline Creatinine & 1.004 & $0.997-1.010$ & 0.257 \\
\hline Activated partial thromboplastin time & 1.051 & $0.974-1.134$ & 0.200 \\
\hline Thrombin time & 1.039 & $0.938-1.150$ & 0.464 \\
\hline D-dimer & 1.039 & $1.004-1.076$ & $0.031 *$ \\
\hline Hypersensitive troponin I & 1.001 & 0.998-1.003 & 0.620 \\
\hline Myoglobin & 1.001 & 0.997-1.005 & 0.749 \\
\hline Oxygen saturation on room air & 0.916 & $0.855-0.981$ & $0.012 *$ \\
\hline $\mathrm{PH}$ & 0.001 & $0.001-7.861$ & 0.135 \\
\hline $\mathrm{PO}_{2}$ & 0.993 & 0.963-1.024 & 0.658 \\
\hline $\mathrm{PCO}_{2}$ & 0.987 & 0.933-1.043 & 0.633 \\
\hline Total lesions score & 1.389 & 1.196-1.613 & $\square 0.001 *$ \\
\hline Main lesion component (GGO/consolidation) & 6.222 & $1.532-25.268$ & $0.011^{*}$ \\
\hline Pleural effusion & 4.636 & $1.834-11.718$ & $0.001 *$ \\
\hline Emphysema & 2.497 & $0.821-7.592$ & 0.107 \\
\hline Hydropericardium & 0.941 & $0.082-10.757$ & 0.961 \\
\hline Pneumomediastinum & 2.033 & $0.546-7.569$ & 0.290 \\
\hline
\end{tabular}

SBP, systolic blood pressure; DBP, diastolic blood pressure; ALT, alanine transaminase; AST, aspartate aminotransferase. * p 00.05 .

Table 5: multivariable study of predictors of mortality risk in patients with severe COVID-19: 


\begin{tabular}{lccc}
\hline & Odds Ratio & $95 \%$ CI & P Values \\
\hline Model 1: baseline characteristics & & & \\
Age & 1.154 & $1.068-1.248$ & $\square 0.001^{*}$ \\
Respiratory rate & 1.127 & $0.990-1.284$ & 0.171 \\
Dyspnea & 1.257 & $0.218-7.259$ & 0.798 \\
Acute respiratory distress syndrome & 14.951 & $3.539-63.171$ & $\square 0.001^{*}$ \\
Cardiovascular disease & 0.439 & $0.081-2.387$ & 0.341 \\
Diabetes & 1.239 & $0.231-6.638$ & 0.802 \\
Hypertension & 0.733 & $0.151-3.562$ & 0.700 \\
Chronic pulmonary disease & 1.795 & $0.323-9.969$ & 0.504 \\
Bacterial infection & 3.257 & $0.558-19.031$ & 0.190 \\
\hline Model 2: laboratory findings & \multicolumn{3}{c}{} \\
\hline Lymphocyte count & 0.001 & $0.001-0.194$ & $0.019 *$ \\
Hemoglobin & 0.914 & $0.800-1.044$ & 0.183 \\
Albumin & 0.872 & $0.586-1.299$ & 0.501 \\
Lactate dehydrogenase & 1.004 & $0.996-1.013$ & 0.305 \\
D-dimer & 0.981 & $0.925-1.041$ & 0.530 \\
Oxygen saturation on room air & 0.914 & $0.800-1.044$ & 0.183 \\
\hline Model 3: HRCT findings & \multicolumn{3}{c}{} \\
\hline Total lesions score & 1.332 & $1.138-1.559$ & $\square 0.001^{*}$ \\
Main lesion component (GGO/consolidation) & 3.408 & $0.710-16.360$ & 0.126 \\
Pleural effusion & 2.070 & $0.693-6.184$ & 0.193 \\
Emphysema & 2.581 & $0.628-10.610$ & 0.189 \\
\hline Model 4: baseline characteristics + Laboratory findings + HRCT findings & \\
\hline Age & 1.142 & $1.059-1.231$ & $0.001^{*}$ \\
Acute respiratory distress syndrome & 10.142 & $1.611-63.853$ & $0.014^{*}$ \\
Lymphocyte count & 0.004 & $0.001-0.306$ & $0.013^{*}$ \\
Total lesions score & 1.276 & $1.002-1.625$ & $0.049 *$ \\
\hline
\end{tabular}

*p匹0.05

Figures 

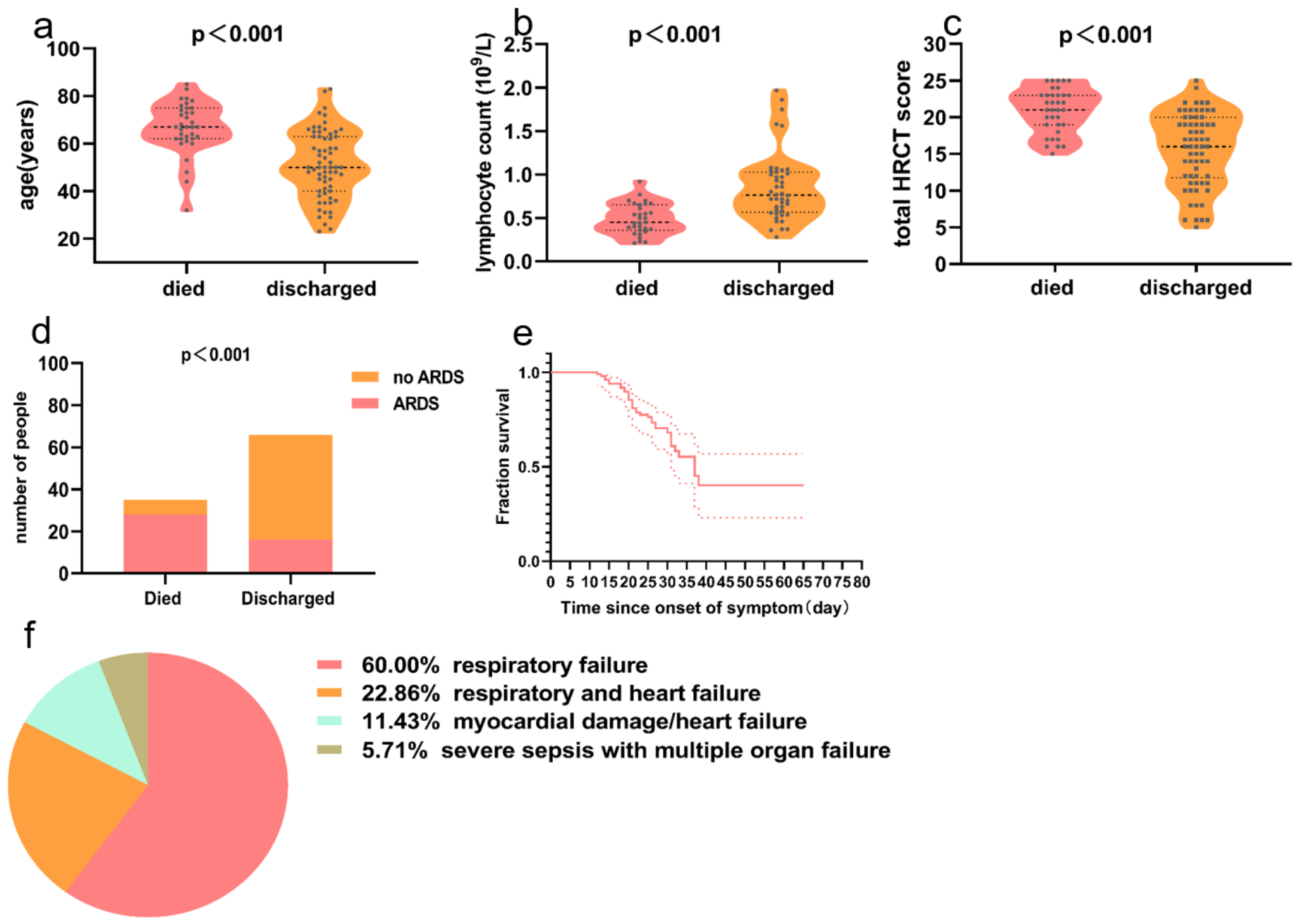

- $60.00 \%$ respiratory failure

- $\mathbf{2 2 . 8 6} \%$ respiratory and heart failure

- $11.43 \%$ myocardial damage/heart failure

- $5.71 \%$ severe sepsis with multiple organ failure

Total=35

\section{Figure 1}

a-d, comparison of age(a), lymphocyte count(b), total HRCT score(c), and ARDS proportion(d) between the died and discharged patients with severe COVID-19. e, survival of patients with severe COVID-19, dashed lines represent $95 \% \mathrm{Cl}$. f, summary of the cause of death of 35 died patients with severe COVID19. 


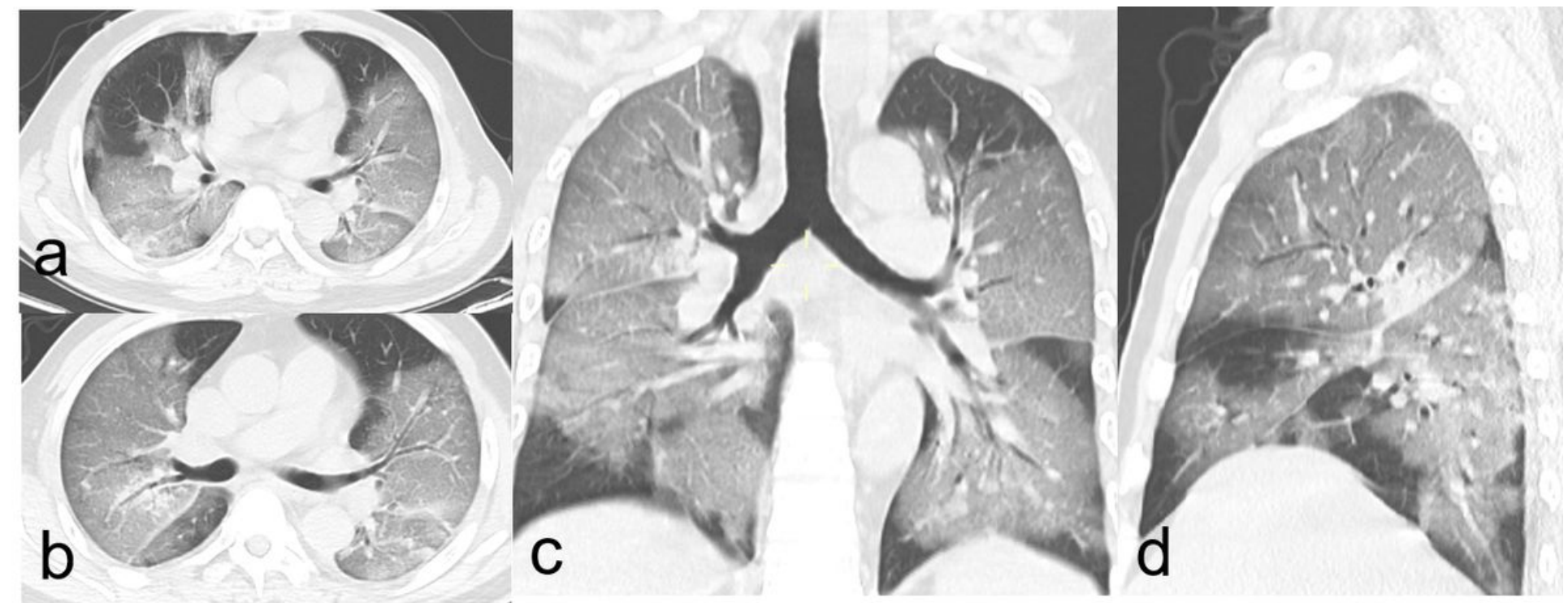

Figure 2

Thin-section CT scans in a man infected with SARS-CoV-2. Scan obtained on 7th day from onset of symptoms shows diffuse ground glass opacities that affected bilateral lung parenchyma. The patient died 10 days after this scan due to respiratory failure.

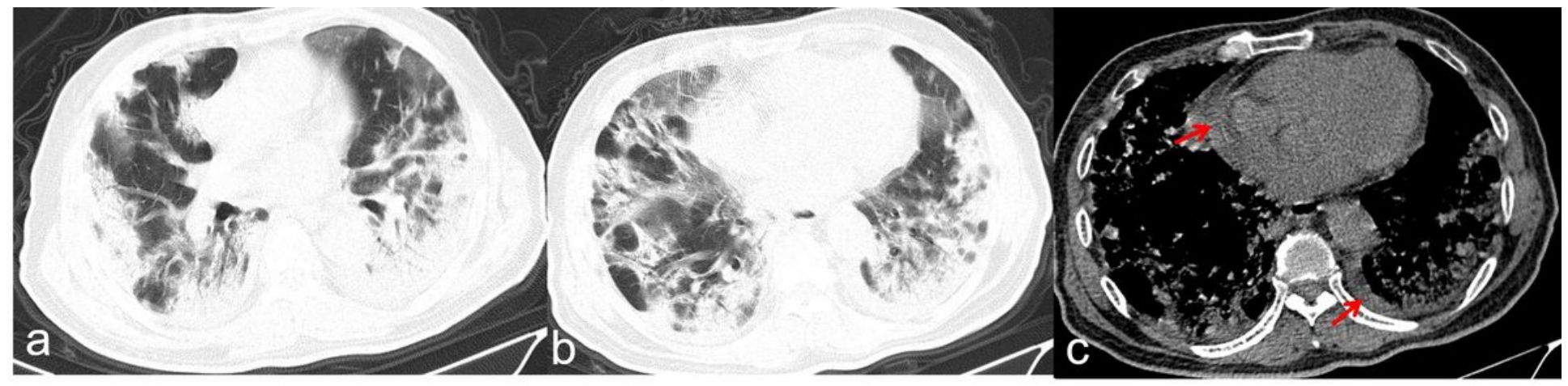

Figure 3

Transverse CT scans in a man infected with SARS-CoV-2 and with type 2 diabetes for 20 years. Scan obtained on 19th day from onset of symptoms shows diffuse, heterogeneous consolidation that affected bilateral lung parenchyma $(a, b)$. The mediastinal window(c) shows a small pleural effusion at the right(arrow) and a small pericardial effusion(arrow). The patient died 4 days after this scan due to respiratory failure. 

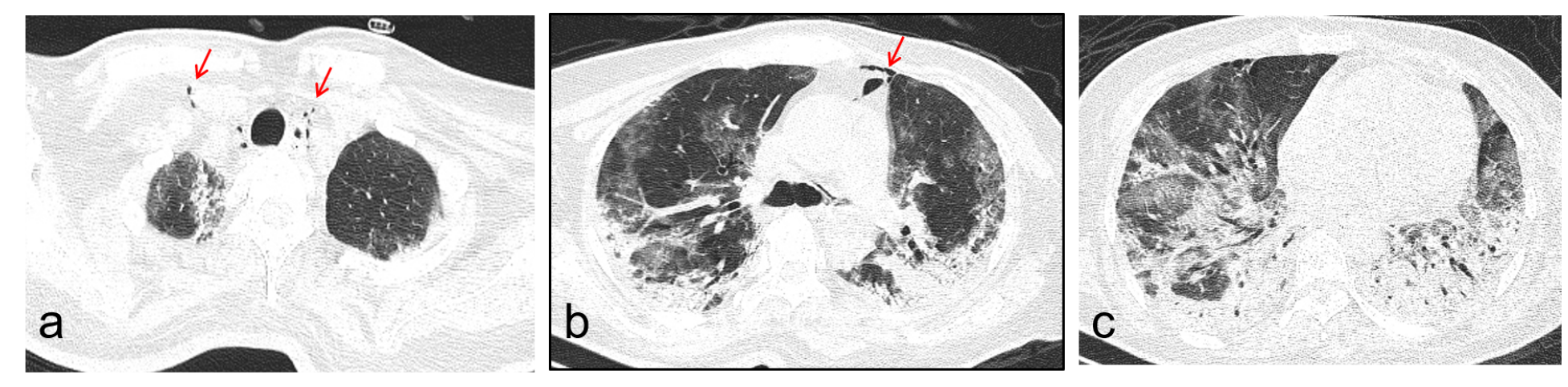

Figure 4

Transverse CT scans in a woman infected with SARS-CoV-2 and suffering type 2 diabetes for 10 years. Scan obtained on 16th day from onset of symptoms shows bilateral, diffuse consolidation, which predominantly involved the lower lobes. There was pneumomediastinum were also seen ( $a, b$ arrows). The patient died 7 days after this scan because of both circulatory and respiratory failure.
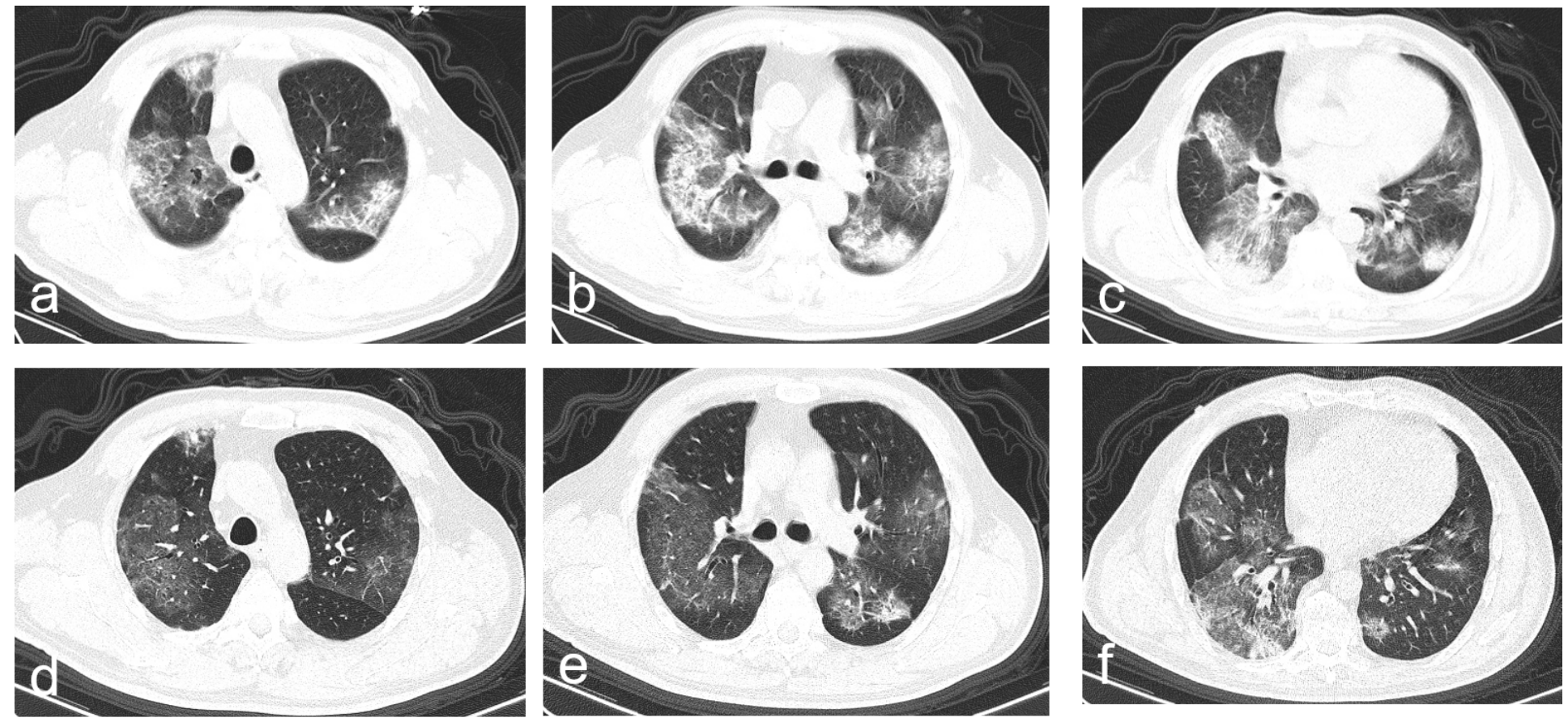

\section{Figure 5}

Transverse CT scans in a man with infected with SARS-CoV-2. Scan (a-c) obtained on 9th day from onset of symptoms shows bilateral, consolidation combined with ground glass opacities. Scan (d-f) obtained on 20th day shows previous consolidation being dissipated into ground-glass opacities. The patient was discharged from hospital 6 days after the final scan. 

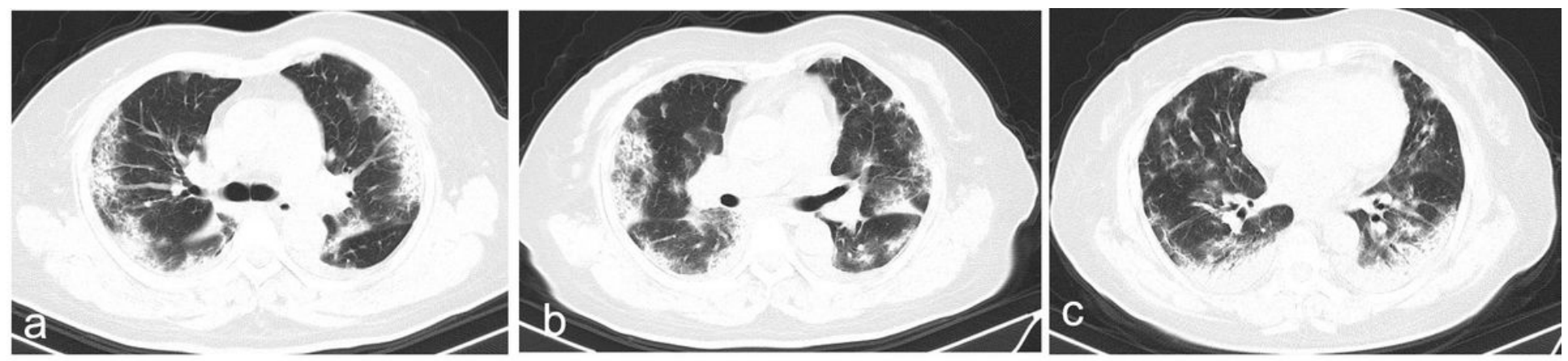

Figure 6

Transverse CT scans in a man infected with SARS-CoV-2. Scan obtained on 10th day from onset of symptoms shows diffuse, heterogeneous consolidation that affected bilateral, subpleural lung parenchyma. The patient was discharged from hospital 7 days the scan.
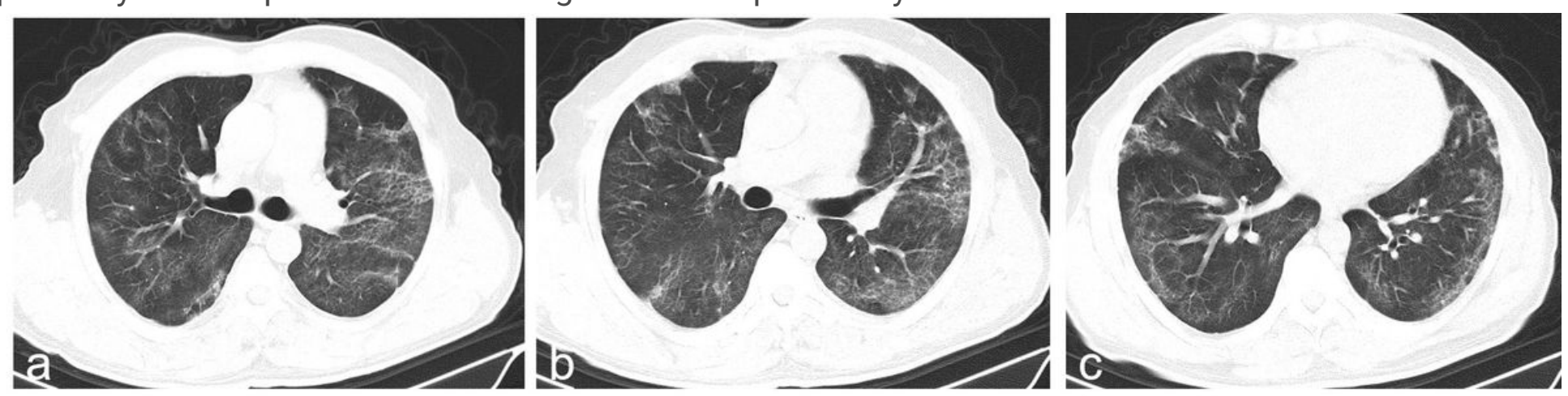

Figure 7

Transverse CT scans in a man with infected with SARS-CoV-2. Scan obtained on 20th day from onset of symptoms shows bilateral, light ground glass opacities with irregular linear opacities. The patient was discharged from hospital 11 days after the scan. 